\title{
Microalgae, macrofauna and sediment stability: an experimental test of a reciprocal relationship
}

\author{
Mark Huxham*, Linda Gilpin, Marina Mocogni, Susan Harper \\ School of Life Sciences, Napier University, Edinburgh EH10 5DT, UK
}

\begin{abstract}
A manipulative field experiment was conducted at Blackness in the Firth of Forth, Scotland, to study the effects of differences in microphytobenthos abundance on sediment stability and macrofauna. Opaque and transparent Perspex was used to construct shaded and controlled treatments, respectively. Shading resulted in significantly lower levels of chlorophyll a recorded from the sediment. Shaded treatments showed significant reductions in populations of Macoma balthica, Hydrobia ulvae and Corophium volutator, 3 of the dominant species at this site. Largely as a result of changes in the abundance of these species, multivariate analyses showed significant differences between shaded and control communities. The impacts of shading on individual species depended on the sediment characteristics. There were no significant differences between treatments in recorded sediment accretion/erosion rates. These results demonstrate the importance of microphytobenthos for the deposit feeders $M$. balthica, $H$. ulvae and $C$. volutator. The absence of any effect on sediment stability might result from the reciprocal, opposite effects of macrofauna and microphytobenthos on sediment stability cancelling each other out in this experiment.
\end{abstract}

KEY WORDS: Microphytobenthos $\cdot$ Macrofauna $\cdot$ Sediment stability $\cdot$ Shading

Resale or republication not permitted without written consent of the publisher

\section{INTRODUCTION}

Benthic microalgae, especially diatoms, are the most significant in situ primary producers in many intertidal and shallow sub-tidal benthic systems; they may contribute more than half of the fixed carbon in an estuary (Underwood \& Kromkamp 1999). These microalgae form an important part of the diet of many deposit feeding invertebrates, as a source of both energy and specific nutritional requirements such as fatty acids (Lopez \& Levinton 1987).

In addition to their trophic function at the base of the foodchain, benthic microalgae (or microphytobenthos) may play an important structural role in some ecosystems. In order to exploit the frequent changes in light intensity experienced on intertidal mudflats, and perhaps to cope with the threats posed by desiccation and grazing, many species in the microphytobenthos show migratory behaviour to and from the mud surface (Taylor \& Paterson 1998). To facilitate this movement, cells secrete mucopolysaccharides or extracellular polymeric substances (EPS) (Smith \& Underwood 1998). Studies in the field (e.g. de Brouwer et al. 2000) and laboratory (e.g. Paterson 1989) have shown that EPS can help stabilise the sediment and increase the critical shear stress required for erosion to take place. Hence, benthic microalgae may play a role in enhancing coastal defence, through the prevention of erosion (Kelly et al. 2001).

Most field studies of the relationships between microphytobenthos, macrofauna and sediment properties have been observational, rather than manipulative. For example, de Brouwer et al. (2000) sampled a sheltered intertidal mudflat over $7 \mathrm{mo}$, and demonstrated significant correlations between chlorophyll and carbohydrate concentrations and sediment accretion. Austen et al. (1999) showed a negative correlation between abundance of the mudsnail Hydrobia ulvae and the erosion threshold of the sediment. Tolhurst et al. (1999) describe the use of a cohesive 
strength meter, which can provide fine scale in situ measurements of critical shear stress and has been used to demonstrate enhanced sediment stability in areas with diatom biofilms. Such studies provide compelling evidence that benthic microalgae can indeed enhance sediment stability and thus potentially alter erosion dynamics on a mudflat. In common with all correlational work, however, they cannot establish causality. Diatoms grow better in silty sediment (van de Koppel et al. 2001), and thus enhanced densities may reflect, rather than cause, sediment accretion. van de Koppel et al. (2001) suggest that positive feedback occurs between enhanced diatom growth and decreased erosion on mud flats, leading to critical thresholds and alternative stable states. The relationship is further complicated by the presence of macrofauna, which may consume the microalgae, and may reduce or enhance shear stress, depending on the species involved and local conditions (Meadows \& Tait 1989). Site-specific factors such as these may explain why concentrations of chlorophyll $a$ are not always a reliable predictor of critical erosion shear stress (Riethmüller et al. 2000), and they underline the importance of field studies in confirming findings from the laboratory.

Manipulative field experiments examining the relationships between microalgae, macrofauna and sediment stability have relied on biocides to remove one or more components of the natural mudflat community. Underwood \& Paterson (1993) used formaldehyde to remove algae and macrofauna from a single $4 \mathrm{~m}^{2}$ site, and found a reduction in sediment bed height compared with a control plot. Daborn et al. (1993) used DCMU (3-(3,4-dichlorophenyl)-1,1-dimethylurea) to inhibit photosynthesis, but did not find prolonged effects because of flushing by the tide. Gerdol \& Hughes (1994) and de Deckere et al. (2001) used insecticides to remove macrofauna, and showed enhanced sediment stability as a result. Interpreting the results of such studies is complicated when the biocides are unselective, thus removing a wide range of organisms with potentially opposing effects. Because they rely on the regular, spaced application of biocide, the treatments may apply 'pulse' rather than 'press' disturbance, which can allow the study of recolonisation (Underwood \& Paterson 1993) but which again can complicate interpretation. In contrast, the present study used a physical method - shading - to provide a selective and prolonged pressure on microalgal communities. We tested 2 null hypotheses:

(1) The removal of microalgal communities by shading has no effect on sediment properties and accretion rates.

(2) The removal of microalgal communities by shading has no effect on macrofauna.

\section{MATERIALS AND METHODS}

Study site. This study was conducted on a sheltered intertidal mudflat located east of the small village of Blackness in the Firth of Forth estuary, East Scotland $\left(56^{\circ} 0^{\prime} \mathrm{N}, 3^{\circ} 30^{\prime} \mathrm{W}\right.$, Fig. 1). Long-term average salinity at the site is 30 .

Experimental set-up and sampling. The experiment was established between mid-tidal and mean low water neap tide (MLWN) levels. The mud in this area has a mean silt content of $34 \%$ and mean organic content of $5.5 \%$. Previous work here has shown that sediment in this apparently homogenous area ranges in silt content from 10 to over $60 \%$, and that the dominant bivalve macrofauna is patchily distributed on scales ranging from $>10 \mathrm{~cm}$ to over $10 \mathrm{~m}$ (Huxham \& Richards 2003). Three treatments were arranged in a replicated, randomised block design. Two blocks, $20 \mathrm{~m}$ apart, each contained 6 plots. Two replicates of each treatment were randomly assigned to plots within each block. Treatments were: (a) Control-an $80 \times 80 \mathrm{~cm}$ plot of mud, unmanipulated except for the insertion of a $1 \mathrm{~m}$ horizontal aluminium bar $12 \mathrm{~cm}$ above the sediment surface, held in place by 2 wooden uprights buried in the sediment on either side of the plot; (b) 'Dark' - an $80 \times 80 \mathrm{~cm}$ shaded treatment; (c) 'Light' an $80 \times 80 \mathrm{~cm}$ 'light' treatment to control for artefacts (Fig. 2).

Dark and light treatments consisted of a central $80 \times$ $80 \mathrm{~cm}$ Perspex sheet, strengthened by a frame made of angle aluminium. Four $10 \times 80 \mathrm{~cm}$ Perspex pieces were loosely hinged at right angles to the larger Perspex sheet to prevent light entering the underlying sediment from more acute angles. So as not to restrict the water flow underneath the structure during tidal immersion, each of these side flaps was equipped with a plastic bottle to act as a float during high tide.

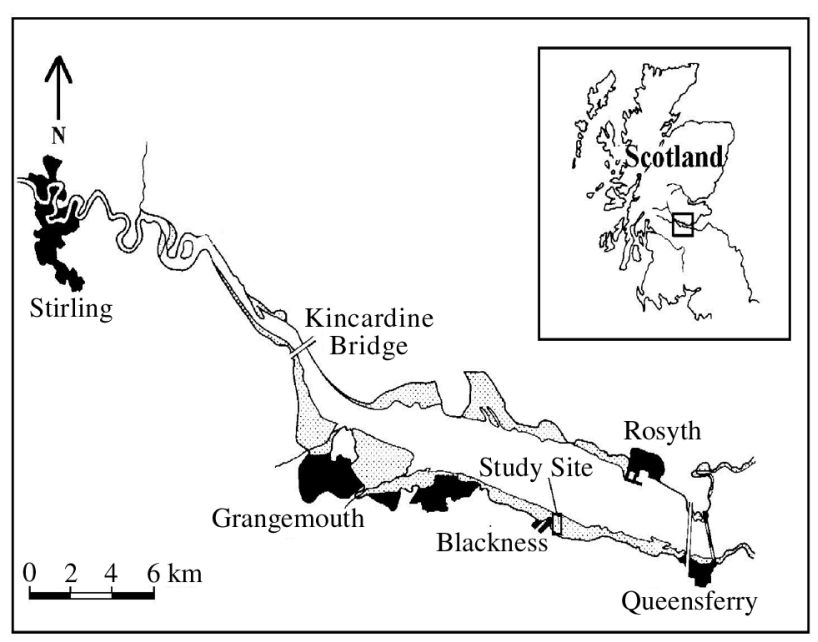

Fig. 1. Location of the field site on the Firth of Forth, Scotland 


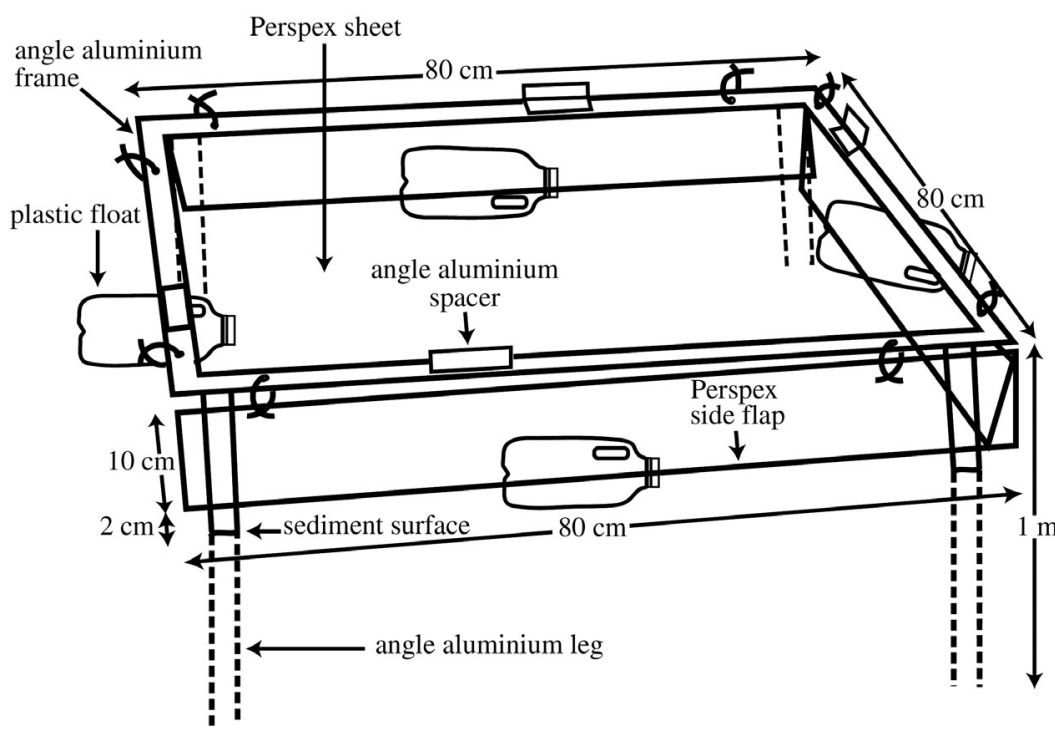

Fig. 2. A 'light' treatment plot, covered by a clear Perspex 'shade', with articulated side flaps designed to float upwards during high tide

absorbance of the supernatant was read at $665 \mathrm{~nm}$ to determine the functional chlorophyll a content and at 750 $\mathrm{nm}$ to correct for turbidity. Acidification with 3 to 4 drops of $1 \mathrm{M} \mathrm{HCl}$ was then performed to convert chlorophyll a to phaeophytin before re-reading at the same wavelengths (Andersen et al. 2001). The chlorophyll a concentration for each of the 16 samples was calculated following the methods in Parsons et al. (1985). (2) Sediment height (each visit): The height downwards from the surface of the Perspex (dark and light treatments) or a marked point in the middle of the horizontal bar (controls) was measured using a thin wire inserted through the central holes of the Perspex treatments (or simply held in place, in the controls). (3) Sediment characteristics (Days 39, 73 and 131): Sediment was sampled at random

Smaller pieces of angle aluminium were riveted to the upper surface of the Perspex sheet to act as spacers, preventing the side flaps from floating more than $180^{\circ}$ upwards and falling back onto the top. Metre-long legs of angle aluminium were riveted to each corner, and each of these structures was pushed into the sediment until the Perspex was $12 \mathrm{~cm}$ above the sediment surface. Dark and light treatments differed only in the former being constructed from opaque, black Perspex, and the latter from transparent Perspex. Measurements with a light meter showed that the dark treatment shaded out $>99 \%$ of natural irradiance, whilst the light blocked $<0.5 \%$. A $6 \mathrm{~mm}$ diameter hole was drilled in the centre of each Perspex sheet to enable subsequent measurements of sediment bed height to be taken.

The experiment was established on 21 March 2003 and was run for $131 \mathrm{~d}$. It was visited for maintenance and monitoring at intervals of approximately $9 \mathrm{~d}$. At each visit, the light treatment was cleaned of silt and any settling organisms to maintain transparency. A light meter recorded $99 \%$ ambient light penetration in the light treatment before cleaning was carried out. The following measurements were taken at each visit or less frequently: (1) sediment chlorophyll a (each visit). Here, 2 surface scrapes of $2.5 \mathrm{ml}$ sediment were taken from 2 random points in each plot (avoiding standing water), using a medical teaspoon, and pooled to a single sample per replicate. On return to the laboratory, samples were frozen until ready for analysis. Pigments were first extracted in $90 \%$ acetone for up to $24 \mathrm{~h}$ in darkness at $4^{\circ} \mathrm{C}$ before being centrifuged at $3500 \mathrm{rpm}(2000 \times g)$ for $8 \mathrm{~min}$. The points to a depth of $3 \mathrm{~cm}$ using a plastic corer of $3 \mathrm{~cm}$ diameter. Four cores were taken for each replicate and then pooled. Water content (weight loss after drying at $70^{\circ} \mathrm{C}$ for $8 \mathrm{~h}$ ) and \% fines (wet sieving over $63 \mu \mathrm{m}$ mesh after mixing with sodium hexametaphosphate) were calculated for each sample. (4) Macrofauna (Days 33 and 131): One $100 \mathrm{~cm}^{2}$ surface area $(10 \times 10 \mathrm{~cm}$ square) core was taken to $5 \mathrm{~cm}$ depth from a random point within each plot, and washed over a $500 \mu \mathrm{m}$ mesh. Retained organisms were identified to species level where possible. (5) Sediment shear strength (Day 131): Shear strength was measured using a Geonor H60 Vane Borer at 3 randomly chosen places in each plot. The borer could not be deployed while the dark and light treatments were in place, hence measurements were taken only at the end of the experiment.

Statistical analyses. After transforming where necessary to meet the requirement of homoscedasticity and normality, data were analysed using univariate and multivariate statistics. Sediment chlorophyll concentrations were compared between treatments, blocks and dates using repeated measures ANOVA. This analysis was supplemented by 2-way ANOVA (here and throughout, blocks were random and treatments fixed factors). Sediment characteristics and univariate measures of macrofauna communities and of dominant species were compared using 2-way ANOVA. MDS (multidimensional scaling) and ANOSIM (analysis of similarity) were employed to explore multivariate structure in the macrofauna community, using the Primer package (Clarke \& Warwick 2001) 


\section{RESULTS}

The main purpose of the treatments - to establish significantly lower densities of microalgae in the dark treatment compared with the light and control treatments - was achieved. Clear differences in chlorophyll a concentrations between the control and light treatments and the dark treatment emerged after $17 \mathrm{~d}$ (Fig. 3), and the dark treatment always had a lower mean concentration than the other treatments after this point. Repeated measures ANOVA showed highly significant between-subjects effects of treatments and blocks (treatments: $\mathrm{df}=2, F=176, \mathrm{p}<0.001$; blocks: $\mathrm{df}=1, F=42, \mathrm{p}=0.001$ ), and within-subjects effects of time. However, there were also significant interaction effects between all factors, and the test failed the assumption of sphericity. A 2-way ANOVA was therefore used to test for differences at each separate sampling time, to give a clearer, and statistically sound, picture of how treatment differences emerged. Of the 13 sampling dates, 6 showed significant treatment differences (Table 1). On the first sampling date, the control treatment had significantly higher levels of chloro-

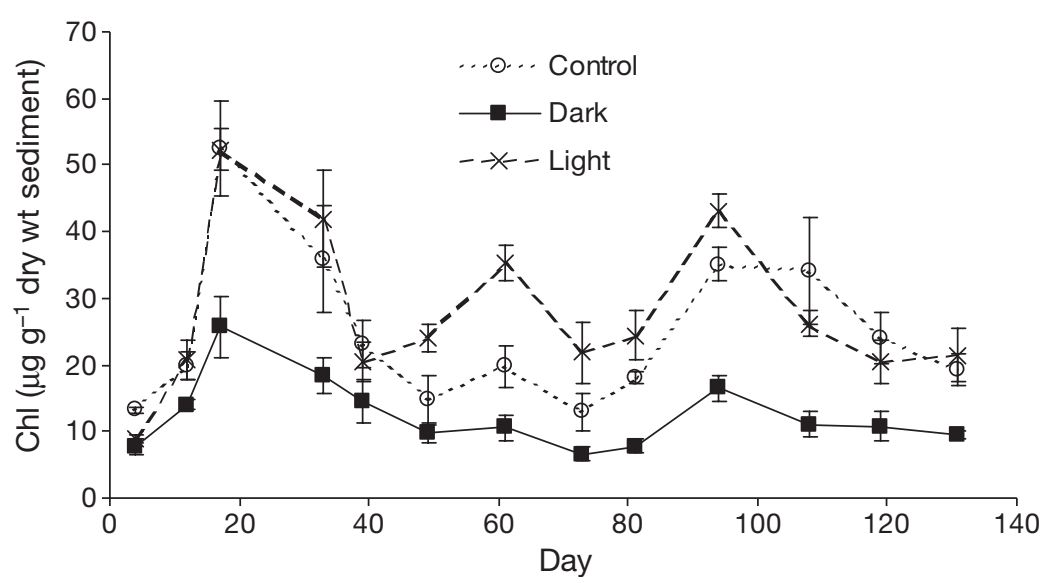

Fig. 3. Mean $( \pm \mathrm{SE})$ chlorophyll a from the 3 treatments on each of the 13 sample days phyll a than the other 2 (perhaps because of the disturbance involved in establishing the experimental treatments); this pattern was never repeated (Table 1). The power of each non-significant test on chlorophyll means was estimated using post-hoc power analyses (Zar 1984, p. 228). These showed that most of these tests had very low power (Table 1), suggesting that non-significant differences on some or all of the dates when they were found could reflect type II error.

In total, 17 taxa of macrofauna were identified. Numerically, the community was dominated by 5 taxa: the prosobranch Hydrobia ulvae (33\% of all individuals in the samples taken on Day 131), the tellinid Macoma balthica (32\% of individuals), the amphipod Corophium volutator (11\%), tubificid oligochaetes (8\%) and the polychaete Pygospio elegans (7\%). No significant differences were found between macrofauna communities in the 3 treatments sampled on Day 33 . By the end of the experiment, however, significant differences had emerged. Community structure was initially analysed using 2-way ANOSIM, with Bray-Curtis similarity measures after square root transformation. This gave a global $\mathrm{R}$ statistic of 0.5 , with an associated $\mathrm{p}$ value of 0.09 . Pairwise tests between treatments were also non-significant. However, the low maximum number of permutations (9) meant that these tests had low power. The MDS plot (Fig. 4) of these data suggested differences were present, with the dark treatment replicates shown as more variable and scattered than the light and control treatments. Differences between blocks were also apparent here, with replicates within blocks clustered together. To increase power, a 1-way ANOSIM was performed ignoring the blocking factor. This gave a global R statistic of 0.375 and a $\mathrm{p}$ value of 0.001 . Maximum permutations for pairwise tests were now 35; significant differences were found

Table 1. Results of 2-way ANOVA for each sampling day, with chlorophyll a as the response variable. Tukey tests showed treatments bracketed together were not significantly different. As an examination of potential type II error, the power of nonsignificant tests is given. ${ }^{*},{ }^{* *},{ }^{* * *}=\mathrm{p}<0.05,0.01,0.001$ respectively; Trt $=$ treatment; $\mathrm{C}=$ control; $\mathrm{L}=$ light; $\mathrm{D}=\mathrm{dark}^{*}$

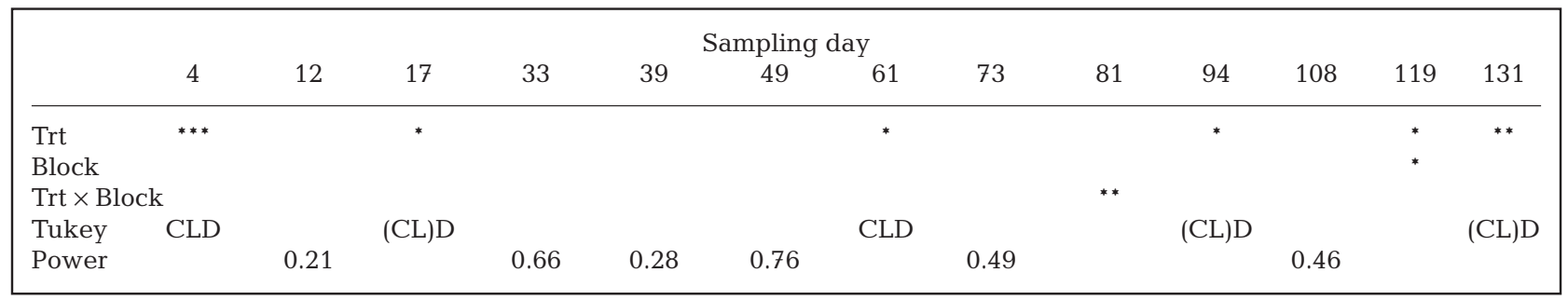




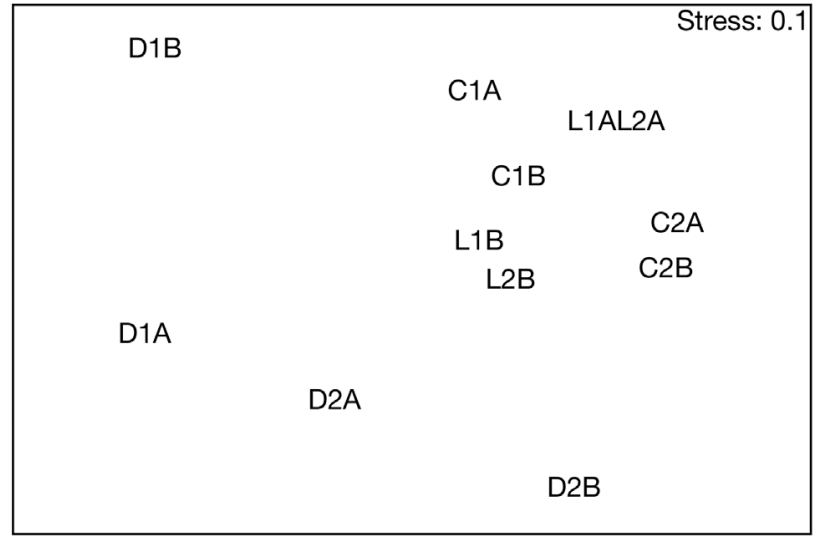

Fig. 4. Multidimensional scaling (MDS) plot of macrofaunal data from the 3 treatments and 2 blocks (stress $=0.1$ ). $\mathrm{L}=$ light, $\mathrm{D}=$ dark, $\mathrm{C}=$ light treatments; $1,2=$ blocks 1 and 2; A, B = within-block replicates A and B

in this analysis between control and dark $(\mathrm{R}=0.54, \mathrm{p}=0.029)$ and light and dark $(\mathrm{R}=$ $0.44, \mathrm{p}=0.029$ ) treatments; no significant difference was found between light and control treatments. Similarity percentage (SIMPER) analyses were performed to identify the taxa contributing most to the dissimilarity between treatments. Those contributing $10 \%$ or more of the total dissimilarity for the 2 significant comparisons were: Control vs. Dark-H. ulvae $(28 \%)$, M. balthica $(18 \%), C$. volutator $(10 \%)$; Light vs. Dark-C. volutator $(23 \%), M$. balthica (14\%), H. ulvae (13\%).

Eight species comprised $1 \%$ or more of the individuals sampled; the mean abundance of these species was compared between treatments (Fig. 5). Large differences were seen for Macoma balthica, Hydrobia ulvae and Corophium volutator. A 2-way ANOVA showed significant differences for $M$. balthica and $H$. ulvae (Table 2). Post-hoc Tukey tests found no significant pairwise differences for $M$. balthica; the power of these tests is less than for 2-way ANOVA because the random block factor is not included. Because of the significant interaction effect with H. ulvae, separate 1-way analyses were performed on data from each block. No significant differences were found for block 1, despite large differences in the mean abundances recorded (mean [SD]: dark 3.5 [3.5]; light 36 [23]; control 43 [5.6]). Because of the small sample size (2) and high pooled variance, the power of this comparison was less than $40 \%$ (post-hoc power analysis, Zar 1984, p. 172). Block 2 showed a highly significant ( $\mathrm{df}=2, F=165, \mathrm{p}=0.001$ ) difference between the high mean number in control plots and the reduced numbers in the light and dark treatments. Block 2 also showed higher mean numbers of $M$. balthica (41 vs. 31 ). There were no $C$. volutator found in the dark treatment, hence statistical comparison was limited to light and dark treatments - light treatments had a significantly higher mean number (Table 2).

There was a significant block effect, but no treatment effect, on shear strength (Table 2). Block 1 had a mean shear strength of $36 \mathrm{~Pa}$, compared with $18 \mathrm{~Pa}$ in block 2. This reflected the higher percentage fines in block 2. There were significant block and interaction effects on \% fines (Table 2). Block 1 had a mean for \% fines of 39, compared with 59 for block 2. A 1-way ANOVA on data taken from each block separately showed a significant difference between control and
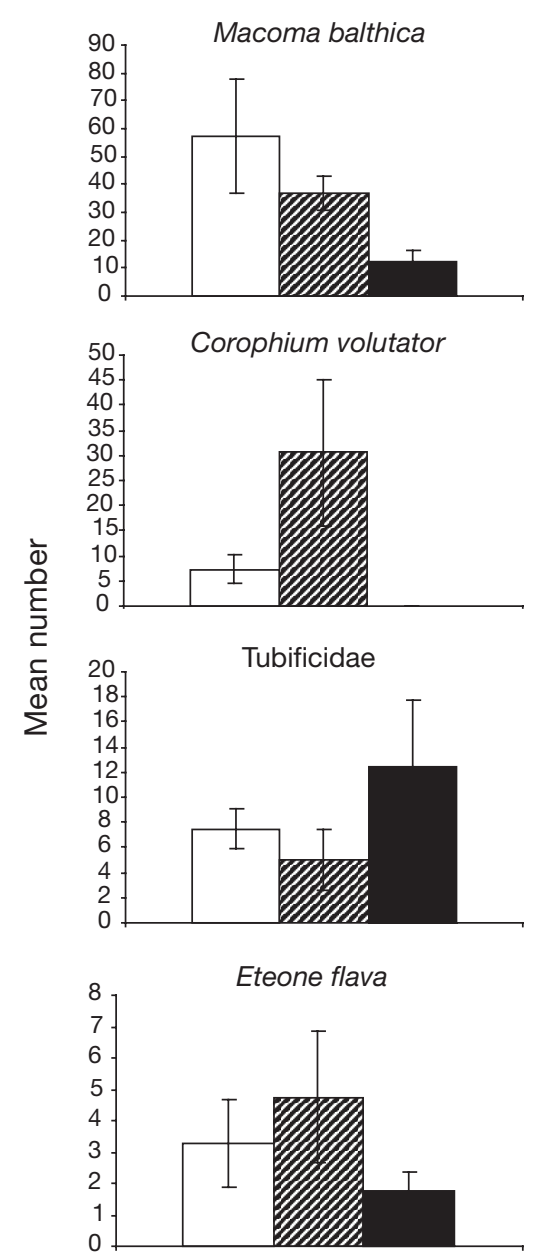
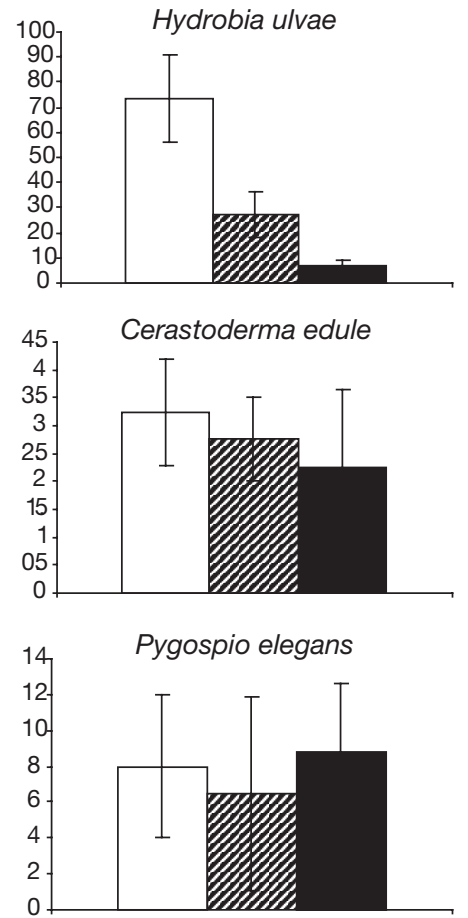

Retusa obtusa

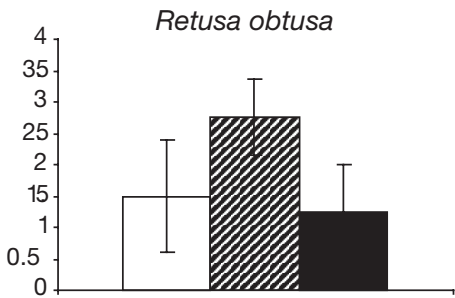

Fig. 5. Mean $( \pm \mathrm{SE})$ abundance per $100 \mathrm{~cm}^{2}$ core of the 8 dominant taxa from control (open), light (shaded) and dark (black) treatments 
Table 2. Results of 2-way ANOVA for treatment and block contrasts for the 3 dominant species that showed significant effects, and for sediment characteristics. Data were taken on the final day of the experiment

\begin{tabular}{|lrrrc|}
\hline Species/Source & df & MS & $F$ & $\mathrm{p}$ \\
\hline Macoma & & & & \\
Treatment & 2 & 2030 & 196 & 0.005 \\
Block & 1 & 280 & 27 & 0.035 \\
Trt $\times$ Block & 2 & 10 & 0.012 & 0.988 \\
Error & 6 & 885 & & \\
Corophium & & & & \\
Treatment & 1 & 1081 & 8646 & 0.007 \\
Block & 1 & 6 & 49 & 0.09 \\
Trt $\times$ Block & 1 & 0.125 & 0 & 0.90 \\
Error & 4 & 673 & & \\
Hydrobia & & & & \\
Treatment & 2 & 4631 & 2.9 & 0.26 \\
Block & 1 & 800 & 0.496 & 0.55 \\
Trt $\times$ Block & 2 & 1613 & 14 & 0.005 \\
Error & 6 & 114 & & \\
Shear strength & & & & \\
Treatment & 2 & 15 & 9 & 0.1 \\
Block & 1 & 978 & 555 & 0.002 \\
Trt $\times$ Block & 2 & 1.7 & 0.08 & 0.9 \\
Error & 6 & 22.6 & & \\
\% fines & & & & \\
Treatment & 2 & 202 & 4 & 0.200 \\
Block & 1 & 1238 & 25 & 0.038 \\
Trt $\times$ Block & 2 & 50 & 8 & 0.018 \\
Error & 6 & 6 & & \\
\hline & & & & \\
\hline
\end{tabular}

dark and light treatments in block $1(\mathrm{df}=2, F=76, \mathrm{p}=$ $0.003)$, with higher mean \% fines in the latter treatments, but no significant difference in block 2 .

Sediment height measures were analysed in 2 ways. First, the mean incremental change since the previous measurement was calculated for each treatment at each sampling time (Fig. 6). Second, the mean total change since the start of the experiment was calculated for each treatment at each sampling time. Repeated measures ANOVA showed no significant dif-

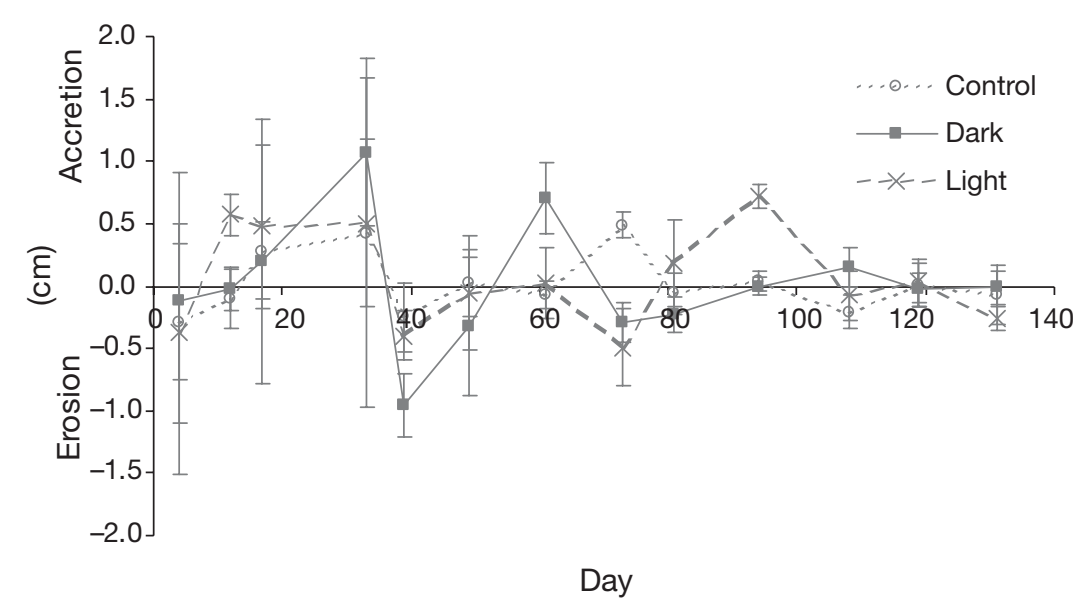

Fig. 6. Mean $( \pm \mathrm{SE})$ incremental change in sediment height in the 3 treatments on each sample day, calculated by measuring down from the centre of the plots ferences within or between-subjects effects. A 2-way ANOVA comparing the total changes in sediment height between treatments at the end of the experiment also showed no significant differences.

\section{DISCUSSION}

Shading the sediment prevented the summer growth of microalgae recorded in the unshaded treatments, resulting in significantly lower chlorophyll a levels in the shaded treatment after $17 \mathrm{~d}$. However, chlorophyll a remained present in the dark treatments throughout the experiment. Some diatoms are adapted to surviving long periods in darkness. For example, Peters (1996) recorded survival times of 35 and $21 \mathrm{~d}$ for 3 temperate pelagic species kept in the dark. Hence, the delay in establishing treatment differences in chlorophyll a concentrations was expected. The continued detection of some chlorophyll in the dark treatment, the concentration of which showed correlations with that found in the other treatments (and hence, presumably, with ambient conditions at the site) suggests that some microalgae were being washed into the dark treatments. However, a clear suppression of microalgal numbers was maintained in the dark treatment for over $100 \mathrm{~d}$. The production of EPS by benthic diatoms ceases after $3 \mathrm{~d}$ in the dark (Smith \& Underwood 2000). Hence, even if diatoms remained alive in the dark treatment, their effects on sediment stability should be minimal.

By the end of the experiment, this reduction in microalgae had caused significant changes in the macrofaunal community in the dark treatments. A number of manipulative studies have considered the impacts of macrofauna on microalgae. Some of these (Underwood \& Paterson 1993, Grant \& Daborn 1994, de Deckere et al. 2001) used biocides with wide spectrum effects, and hence looked at the effects of the whole macro and meiofaunal communities. Most authors suggest that the net effects of macrofauna are destabilising, and these studies lend support to this conclusion. They give a more mixed message on the potential impacts of macrofauna on microalgae, with Underwood \& Paterson (1993) demonstrating enhanced diatom growth in the absence of fauna, and de Deckere et al. (2001) showing no differences after faunal removal. These discrepancies may be explained by differences in time span and in the use of an insecticide by de Deckere et al. (2001), rather than of formalde- 
hyde - the latter kills all the biota, and thus may produce 'overshoot' effects on microalgae population growth (Byers 2000). Other work has focused on particular taxa, such as Hydrobiid snails (Fenchel \& Kofoed 1976), Corophium volutator (Gerdol \& Hughes 1994, Smith et al. 1996) Neries diversicolor (Smith et al. 1996) and Cerithidea californica (Byers 2000). All these studies have demonstrated the potential for consumers to control microalgal numbers. The obvious corollary, that benthic microalgae may control populations of their consumers, has received less attention from experimentalists. Studies by Dauer et al. (1982) and Wiltse et al. (1984) that involved fertilising soft-bottom plots failed to show large increases in macrofauna. The work by Stocks \& Grassle (2001) provides the closest comparison to the present study. They used shading to reduce microalgae in artificial pools established in a saltmarsh. Their experiment ran for $60 \mathrm{~d}$, and resulted in significantly lower populations of 3 dominant macrofauna taxa in the shaded treatment. They also demonstrated reduced dissolved oxygen levels in their shaded pools, a factor which may have contributed to the macrofaunal response. Reduced oxygen output could be viewed as a possible artefact of shading, or as a logically necessary part of the experimental treatment (since suppressing primary production will have this effect); the exact interpretation must depend on the null hypothesis being tested (for example, whether food resources alone, or the effects of the microalgal community as a whole, are the focus of interest). Oxygen levels were not measured in the present work since there was no standing water; sediment was exposed to the air and flushed by tides twice daily. Hence differences in oxygenation are unlikely to have influenced the results found. Stocks \& Grassle (2001) also reported that shading reduced mean maximum temperatures of their ponds by $1.9^{\circ} \mathrm{C}$. Pilot work over $3 \mathrm{wk}$ at the current site found no impact of shading on temperature, and any effects that occurred are likely to be small compared with the Stocks \& Grassle (2001) study, again because of the difference between standing pools and an open, flushed mudflat. Although other treatment-specific artefacts are possible, and are discussed below, it is as a food resource that the different levels of microalgae established in the treatments are most likely to have influenced macrofauna.

The results of the current study thus provide confirmation of the importance of microalgae in the diets of the deposit feeding species Corophium volutator, Hydrobia ulvae and Macoma balthica. These 3 species were numerically dominant at the field site, and contributed most of the dissimilarity between the macrofaunal communities in the dark treatment and those in the light and control treatments. C. volutator was entirely absent from the dark treatments (Fig. 5). It also showed a significant increase in the light, compared with the control, treatment, suggesting a treatmentspecific artefact favouring this species. There is evidence that microalgal growth was enhanced under the light treatment, compared with the control; higher levels of chlorophyll a were recorded from this treatment for much of the experiment (Fig. 3), and these were significantly higher on Day 61 (Table 1). Hence, the higher numbers of $C$. volutator may reflect this increased resource. The cause of this treatment-specific effect is not known. Microalgal production can be reduced under conditions of high irradiance (Perkins et al. 2001); hence it is possible that the slight shading effect of the light treatments enhanced microalgal growth. An alternative, or supplementary, explanation for the enhanced abundance of $C$. volutator in the light treatments is that these provided refuge from predation by birds, whilst still allowing feeding. Daborn et al. (1993) provide evidence of significant reductions in C. volutator abundance caused by bird predation. C. volutator is a deposit feeder that relies heavily on microalgae (Gerdol \& Hughes 1994). Hence, its absence from the dark treatment plots is expected, and suggests that any ability it may have to suspension feed (Smith et al. 1996) is of limited importance.

Although Hydrobia ulvae was important in driving the significant multivariate differences recorded between dark and unshaded treatments, univariate analyses of mean density show a complex picture. Overall, there was a non-significant reduction in abundance in the light and dark treatments, but interpretation is complicated by the significant interaction effect. Block 1 showed a large reduction in the mean numbers recorded in the dark treatment; the non-significance of this result is probably a type II error caused by the low sample size resulting from analysing the blocks separately. Block 2 showed a different pattern, with numbers of snails reduced in the dark and light treatments, compared with the control. This suggests an interaction between the block and an artefact caused by the Perspex structures. Experimental interventions inevitably cause artefacts. At intertidal sites, these artefacts often arise as a result of changes in water flow and sedimentation caused by physical structures. The significantly higher percentage fines found in the Perspex treatments at block 1 suggest that these structures were having an effect on sedimentation. Hence, this might be implicated in the response of the $H$. ulvae in the Perspex treatments in block 2, (although no significant effects were found on sediment in this block, so another, undetected, artefact may be the cause). $H$. ulvae is known to deposit feed on microalgae (Fenchel \& Kofoed 1976). Hence, the overall pattern of reduced abundance in the dark treatment was expected. Explaining the more detailed results, how- 
ever, is more difficult. For example, it is surprising that $H$. ulvae did not follow the pattern shown by Corophium volutator in having higher, or at least similar, abundance in the light treatment compared with controls. Hagerthey et al. (2002) investigated the impacts of grazing by $C$. volutator and $H$. ulvae on microalgal community structure. They found that $H$. ulvae was a relatively generalist consumer compared with $C$. volutator; the former tended to graze subdominant species whilst the amphipod specialised in the dominant taxa. Hence, the effects of the 2 invertebrates were different, with $C$. volutator enhancing microalgal diversity and $H$. ulvae having little impact. The greater abundance of $C$. volutator in the light treatment may have reflected not only enhanced chlorophyll a levels, but also a different microalgal community structure in which dominant species were favoured by the better conditions. Such a scenario might benefit $C$. volutator over $H$. ulvae, given their different feeding preferences.

Macoma balthica showed significant differences between the 3 treatments, although these were proportionately smaller than those for the other 2 main species. This may reflect the ability of post-juvenile M. balthica to adopt suspension, as well as deposit, feeding (Lin \& Hines 1994), thus reducing its dependence on benthic food sources such as microalgae. The absence of any significant treatment impacts on Cerastoderma edule, an obligate suspension feeder (Kamermans et al. 1992), further supports the suggestion that the microphytobenthos are important for deposit, but not suspension, feeding organisms. The present results suggest that benthic microalgae are not important sources of food at this site for the other main species of macrofauna sampled. They also show that reducing or removing dominant species from the macrofauna may have little or no effect on the remaining species, a result consistent with the suggestion that competitive forces (and particularly competition for space) do not structure macrofaunal communities at Blackness (Huxham et al. 2002).

The present study is anomalous in failing to find any significant impact of microphytobenthos on sediment accretion rates; the first null hypothesis cannot be rejected. A large literature documents positive correlations between microphytobenthos and sediment stability and accretion. This study differs from most of this work in being experimental, rather than observational, and in selectively removing microalgae. The main impact of this removal - the reductions in populations of macrofaunal species - may explain the absence of significant effects on sediment accretion. Austen et al. (1999) showed a highly significant, positive correlation between sediment chlorophyll levels and erosion thresholds. They also demonstrated a highly signifi- cant negative influence of Hydrobia ulvae on sediment stability, a result that concurs with other work on the destabilising effects of macrofauna (de Deckere et al. 2001). Hence, these 2 influences may counter-balance one another. In the current work, the dark treatment had significantly lower populations of microphytobenthos and of macrofaunal grazers, which may have resulted in no net effects on sediment stability. If this is true, it suggests that microphytobenthos will have its largest impacts on sediment erosion when and where it escapes the influence of grazers, such as when macrofaunal numbers are themselves suppressed by predation (Daborn et al. 1993).

Acknowledgements. We thank S. Jones and Fantastic Fabrications for help with the design and construction of the experiment. The comments of an anonymous referee helped to improve the manuscript.

\section{LITERATURE CITED}

Andersen TJ (2001) Seasonal variation in erodibility of two temperate, microtidal mudflats. Estuar Coast Shelf Sci 53: $1-12$

Austen I, Andersen TJ, Edelvang K (1999) The influence of benthic diatoms and invertebrates on the erodibility of an intertidal mudflat, the Danish Wadden Sea. Estuar Coast Shelf Sci 49:99-111

Byers JE (2000) Competition between two estuarine snails: implications for invasions of exotic species. Ecology 81: 1225-1239

Clarke KR, Warwick RM (2001) Changes in marine communities: an approach to statistical analysis and interpretation, 2nd edn. PRIMER-E, Plymouth

Daborn G, Amos C, Brylinsky M, Christian H, Drapeau G (1993) An ecological cascade effect: Migratory birds affect stability of intertidal sediments. Limnol Oceanogr 38: 225-231

Dauer DM, Ewing RM, Tourtellotte GH, Harlan WT, Sourbeer JW, Barker HR (1982) Predation, resource limitation and the structure of benthic infaunal communities of the lower Chesapeake Bay. Int Rev Gesamten Hydrobiol 67:477-489

de Brouwer JFC, Bjelic S, de Deckere E, Stal LJ (2000) Interplay between biology and sedimentology in a mudflat (Biezelingse Ham, Westershelde, The Netherlands) Contin Shelf Res 20:1159-1177

de Deckere EMGT, Tolhurst TJ, de Brouwer JFC(2001) Destabilisation of cohesive intertidal sediments by infauna. Estuar Coast Shelf Sci 53:665-669

Fenchel T, Kofoed LH (1976) Evidence for exploitative interspecific competition in mud snails (Hydrobiidae). Oikos $27: 367-376$

Gerdol V, Hughes RG (1994) Effect of Corophium volutator on the abundance of benthic diatoms, bacteria and sediment stability in 2 estuaries in southeastern England. Mar Ecol Prog Ser 114:109-115

Grant J, Daborn G (1994) The effects of bioturbation on sediment transport on an intertidal mudflat. Neth J Sea Res 32: 63-72

Hagerthey SE, Defew EC, Paterson DM (2002) Influence of Corophium volutator and Hydrobia ulvae on intertidal benthic diatom assemblages under different nutrient and 
temperature regimes. Mar Ecol Prog Ser 245:47-59

Huxham M, Richards M (2003) Can post-larval bivalves select sediment type during settlement? A field test with Macoma balthica (L.) and Cerastoderma edule (L.). J Exp Mar Biol Ecol 288:279-293

Huxham M, Roberts I, Bremner J (2000) A field test of the intermediate disturbance hypothesis in the soft-bottom intertidal. Int Rev Hydrobiol 8:379-394

Kamermans P, van der Veer H, Karczmarski L, Doeglas G (1992) Competition in deposit- and suspension-feeding bivalves: experience in controlled outdoor environments. J Exp Mar Biol Ecol 162:113-135

Kelly JA, Honeywill C, Paterson DM (2001) Microscale analysis of chlorophyll $a$ in cohesive intertidal sediments: the implications of microphytobenthos distribution. J Mar Biol Assoc UK 81:151-162

Lin J, Hines A (1994) Effects of suspended food availability on the feeding mode and burial depth of the Baltic clam, Macoma balthica. Oikos 69:28-36

Lopez G, Levinton J (1987) Ecology of deposit-feeding animals in marine sediments. Q Rev Biol 62:235-260

Meadows PS, Tait J (1989) Modification of sediment permeability and shear strength by two burrowing invertebrates. Mar Biol 101:75-82

Parsons TR, Yoshiaki M, Lalli CM (1985) A manual of chemical and biological methods for seawater analysis. Pergamon Press, Oxford, p 104-06

Paterson D (1989) Short-term changes in the erodibility of intertidal cohesive sediments related to the migratory behaviour of epipelic diatoms. Limnol Oceanogr 34:223-234

Perkins RG, Underwood GJC, Brotas V, Snow GC, Jesus B, Ribeiro L (2001) Responses of microphytobenthos to light: primary production and carbohydrate allocation over an emersion period. Mar Ecol Prog Ser 223:101-112

Peters E (1996) Prolonged darkness and diatom mortality: II Marine temperate species. J Exp Mar Biol Ecol 207:43-58

Riethmuller R, Heineke M, Kuhl H, Keuker-Rudiger R (2000)

Editorial responsibility: John Gray (Contributing Editor), Oslo, Norway
Chlorophyll a concentration as an index of sediment surface stabilisation by microphytobenthos. Contin Shelf Res 20:1351-1372

Smith DJ, Underwood GJC (2000) The production of extracellular carbohydrates by estuarine benthic diatoms: the effects of growth phase and light and dark treatment. J Phycol 36:321-333

Smith D, Hughes RG, Cox EJ (1996) Predation of epipelic diatoms by the amphipod Corophium volutator and the polychaete Nereis diversicolor. Mar Ecol Prog Ser 145: 53-61

Stocks KI, Grassle JF (2001) Effects of microalgae and food limitation on the recolonization of benthic macrofauna into in situ saltmarsh-pond mesocosms. Mar Ecol Prog Ser 221:93-104

Taylor IS, Paterson DM (1998) Microspatial variation in carbohydrate concentrations with depth in the upper millimetres of intertidal cohesive sediments. Estuar Coast Shelf Sci 46:359-370

Tolhurst TJ, Black KS, Shayler SA, Mather S, Black I, Baker K, Paterson DM (1999) Measuring the in situ erosion shear stress of intertidal sediments with the cohesive strength meter (CSM). Estuar Coast Shelf Sci 49:281-294

Underwood GJC, Paterson DM (1993) Recovery of intertidal benthic diatoms after biocide treatment and associated sediment dynamics. J Mar Biol Assoc UK 73:25-45

Underwood GJC, Kromkamp J (1999) Primary production by phytoplankton and microphytobenthos in estuaries. Adv Ecol Res 29:93-153

van de Koppel J, Herman PMJ, Thoolen P, Heip CHR (2001) Do alternate stable states occur in natural ecosystems? Evidence from a tidal flat. Ecology 82:3449-3461

Wiltse WI, Foreman KH, Teal JM, Valiela I (1984) Effects of predators and food resources on the marobenthos of salt marsh creeks. J Mar Res 42:923-942

Zar JH (1984) Biostatistical Analysis, 2nd edn. Prentice-Hall, Englewood Cliffs, NJ

Submitted: January 14, 2005; Accepted: September 5, 2005 Proofs received from author(s): February 9, 2006 